\title{
An Exploratory Analysis of Microcosm and Ecosystem Behavior Using Multivariate Techniques
}

\author{
C. A. Oviatt, H. Walker and M. E. Q. Pilson \\ Graduate School of Oceanography, University of Rhode Island Kingston, Rhode Island 02881, USA
}

\begin{abstract}
A conservative data set was chosen to describe ecosystem behavior: total zooplankton (mg dry wt $\mathrm{m}^{-3}$ ), chlorophyll a $\left(\mu \mathrm{g} \mathrm{l}^{-1}\right)$, ammonia, nitrite, plus nitrate, phosphate and silicate $\left(\mu \mathrm{g}\right.$-at $\left.\mathrm{l}^{-1}\right)$. These variables were measured weekly in the microcosms, as well as in a field survey of Narragansett Bay in 1972-73; thus a comparison data set was available. Two types of statistical techniques were used to explore the question of divergence among replicate microcosms and treatment groups (including the bay stations as treatment groups): Multiple Discriminant Analysis and Distance Statistics. The first was used to explore the major axes of variation between replicate tanks and bay stations. Distance statistics were used to describe the divergence of replicate tanks and treatment groups as a function of time. The first distance analysis was based on discriminant space using the pooled covariance matrix and the distances were weighed by the percent variation explained by the axes. The second distance analysis did not rely on discriminant space and the distances were based on estimations of the individual covariance matrices rather than the pooled covariance matrix. Discriminant analyses were employed to explore the major axes of variations between microcosm treatments and the natural system. Generally only the first axis was interpretable. In the microcosm perturbation experiment, the first axis was interpreted to be indicative of bloom conditions. When the microcosms and the bay were analysed, the first axis was interpreted as an eutrophication gradient. In addition, time varying plots were made to indicate differences due to treatment and season. The two distances indicated obvious features in the divergence among replicate tanks and within bay areas and between treatment groups and bay areas. With both distance statistics, the divergence among replicate tanks within a treatment could be related to lag effects in the dynamics of plankton blooms. Divergence among treatment groups could be related to substantial changes in the functional behavior of the microcosms. The natural logarithm of the determinant of individual covariance provided evidence that the bay stations were more variable than the microcosms. The question remains as to whether the techniques we have used are more useful than visually interpreting plots of the response of the individual variables over time. The attempts to reduce the dimensionality of the representation space did provide a summarization of the data and resulted in interpretations in agreement with raw data time series analyses. The distance metrics have roughly quantified the magnitude of divergence in microcosm behavior and compared the behavior with the natural system.
\end{abstract}

\section{INTRODUCTION}

During the last two years we have been experimenting with intermediate-sized microcosms intended to be analogues of a coastal marine ecosystem. The microcosms contain coupled planktonic and benthic communities, and have been run and intensively sampled continuously for more than one year. During this time we have obtained data from 9 microcosms and, for comparison with the natural system, from the adjacent Narragansett Bay. During experimental periods the microcosms were run in triplicate as controls or experimental treatments. We have used standard statistical methods and developed new ways to compare the microcosms with each other and the Bay, using the many different kinds of data obtained.
In the study of whole ecosystems, it has not yet been possible to develop single measures or other accepted methods to compare their states or conditions. Each ecosystem is a complex of many variables and processes changing with time. In attempting to compare the behavior of our microcosms with each other and with the Bay we are, therefore, in some quandary. The microcosm approach is relatively new, and no adequate criteria have been developed that can be used to assess the state of these enclosed ecosystems. In considering possible holistic similarities we tend to think of similar patterns in the seasonal cycling of a number of variables, but we do not know how to define these precisely. It is not clear which variables might be important, and how similar the patterns should be. Results from the large in situ microcosms at Kiel, FRG 
(Bodungen et al., 1976; Smetacek et al., 1976), Lock Ewe (Davies et al, 1975) and British Columbia, Can. (CEPEX) (Hood, 1977; Menzel, 1977) have only recently been published. These facilities are so large and expensive that it has often been necessary to run them with little or no replication. Furthermore, with perhaps one exception (Perez et al., 1977), both big and small marine microcosms, used to explore simplified systems, have been run with little attention to physical and biotic scaling.

In earlier microcosm experinents we have used multivariate analysis to study how a set of variables with complex interaction can be reduced to a fewer number of dimensions displaying differences in microcosm behavior, and differences between the microcosms with the natural system (Oviatt et al., 1977; Oviatt et al., 1979; Pilson et al., 1979). In these studies, we had difficulties in interpreting the meaning of the multivariate analyses but in the present paper we have attempted to interpret the results in detail. Also, we have attempted to find methods for quantifying differences through the use of distance metrics.

\section{Facility and Experiments}

The Marine Ecosystems Research Laboratory (MERL) microcosms are small enough $\left(14 \mathrm{~m}^{3}\right)$ to allow for replication, yet still large enough to retain much of the complexity of the real system (Pilson et al., 1977), and to allow repeated sampling without exhaustion. They were physically scaled to nature as well as we know how. The microcosms (Fig. 1) received sunlight; they had a $5.5 \mathrm{~m}$ water column and $30 \mathrm{~cm}$ of sediment containing a heterotrophic benthic community; they were mixed by plungers designed to resuspend bottom sediments as tidal currents do in nature; they received new water to provide a turnover time of $27 \mathrm{~d}$; their walls were cleaned to prevent dominance by fouling communities. The temperature range in the tanks and in the bay was $\sim-1$ to $25 \mathrm{C}^{\circ}$ over the seasonal cycle. The salinity range in both was quite small ranging from $27 \%$ to $31 \%$

The first experiments began in August 1976. For the first 4 months the microcosms were run as replicates (Table 1) and behaved very similarly to one another and to the adjacent natural system, Narragansett Bay (Pilson et al., 1979). In December a single addition of \# 2 fuel oil at a concentration of $150 \mathrm{ppb}$ was introduced into three of the microcosms. Late in December input water feed lines froze and all microcosms were operated without input water for about 5 weeks. In early February the water flow was restarted in six tanks while three tanks remained in "batch mode" until August 1, 1977 when water flow was started

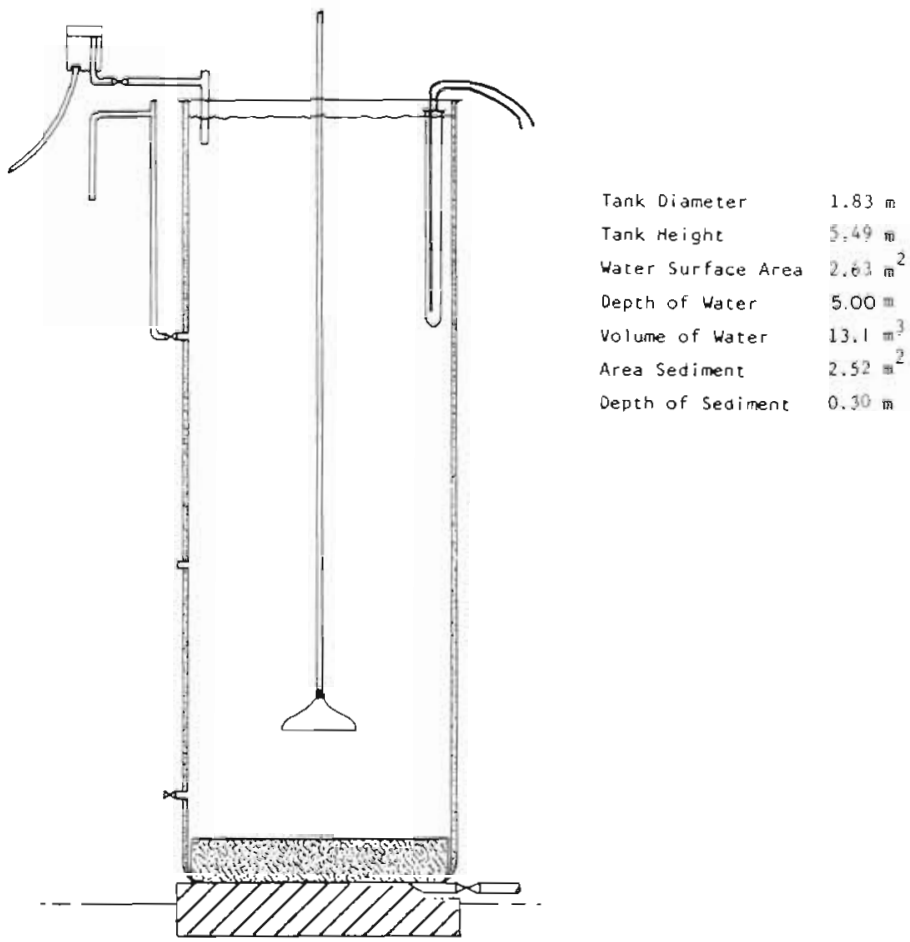

Fig. 1. Diagramatic view of a microcosm. New water (120 l) flows into the tank every $6 \mathrm{~h}$. The outflow is located about $1 \mathrm{~m}$ below the water surface. A plunger mixes the tank on a schedule of $2 \mathrm{~h}$ on and $4 \mathrm{~h}$ off. The walls are insulated, and a heat exchanger helps to maintain the temperature to within $\pm 2 \mathrm{C}^{\circ}$ of the bay water temperature

Table 1. Outline of MERL experimental treatments, $1976-1977$

\begin{tabular}{|c|c|c|c|}
\hline & Tanks 1,5,8 & $\begin{array}{l}\text { Treatment } \\
\text { Tanks } 3,4,6\end{array}$ & Tanks 2,7,9 \\
\hline \multicolumn{4}{|l|}{1976} \\
\hline August & Control & Control & Control \\
\hline September & Control & Control & Control \\
\hline October & Control & Control & Control \\
\hline November & Control & Control & Control \\
\hline December & Control & Control & Control \\
\hline \multicolumn{4}{|l|}{1977} \\
\hline January & Batch & Batch & Batch \\
\hline February & Control & Batch & Oil \\
\hline March & Control & Batch & Oil \\
\hline April & Control & Batch & Oil \\
\hline May & Control & Batch & Oil \\
\hline June & Control & Batch & Oil \\
\hline July & Control & Batch & Oil \\
\hline August & Control & Recovery & Recovery \\
\hline September & Control & Recovery & Recovery \\
\hline
\end{tabular}

again. Beginning in early February bi-weekly additions of \# 2 fuel oil were made to the three tanks previously dosed with oil (Gearing et al., 1979). These additions were such as to maintain a concentration 
averaging about $190 \mathrm{ppb}$. Oil addition stopped on August 1, 1977, and the rate of recovery was observed until the experiment was terminated in mid-September.

\section{METHODS}

\section{Variables}

During these experiments, plankton, benthos, nutrients, trace metals and hydrocarbons were routinely monitored, generating large data sets in each category.

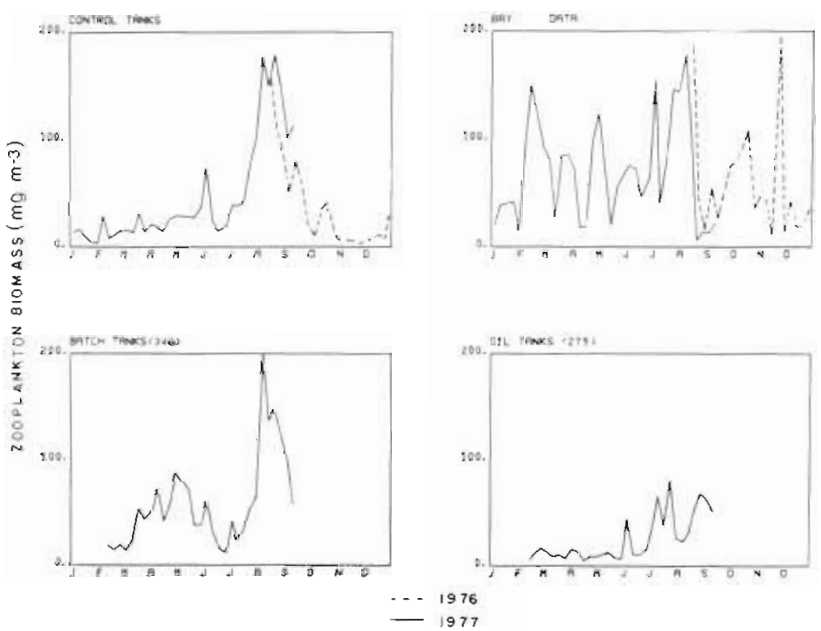

Fig. 2. Mean chlorophyll concentrations from weekly measurements in 9 control tanks (all running as replicates) from August to December 1976 and in 3 control tanks $(1,5,8)$ from December 1976 to September 1977. Chlorophyll concentrations from the bay were obtained from single samples taken weekly at G.S.O. dock. Chlorophyll concentrations for the 3 batch tanks and the oil tanks shown only for treatment and recovery periods from mid-February to mid-September 1977 Broken lines: August to December 1966; solid lines: January to September 1977

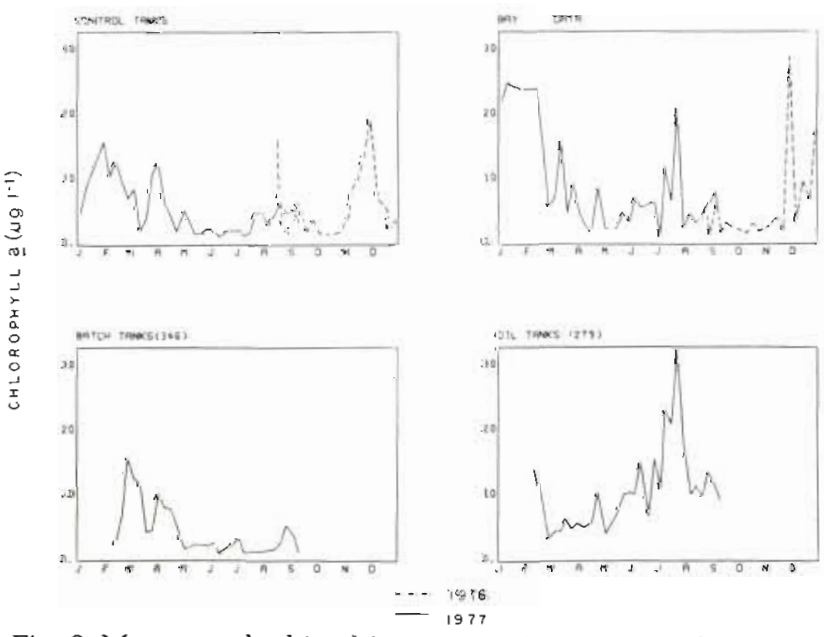

Fig. 3. Mean zooplankton biomass in microcosms and one bay station at G.S.O. dock. See Figure 2 for number of tanks and sample periods
In this paper we have chosen the following set of variables to describe the ecosystem behavior: total zooplankton ( $\mathrm{mg}$ dry wt $\mathrm{m}^{-3}$ ) (Tranter, 1968; Steedman, 1976), chlorophyll a ( $\mu \mathrm{g} \mathrm{l}^{-1}$ ) (Holm-Hansen et al,, 1965; Lorenzen, 1965), ammonia, nitrite plus nitrate, phosphate and silicate ( $\mu$ g-at $1^{-1}$ ) (Solórzano, 1969; Frederick and Whitledge, 1972; Degobbis, 1973) (Figs $2-7$ ). These variables were chosen because they were measured frequently (weekly), and because the same set was measured in a field survey of Narragansett Bay in $1972-73$ (Fig. 8). These variables represent the important components of the water column (plankton); they are influenced by benthic regeneration of nutrients.
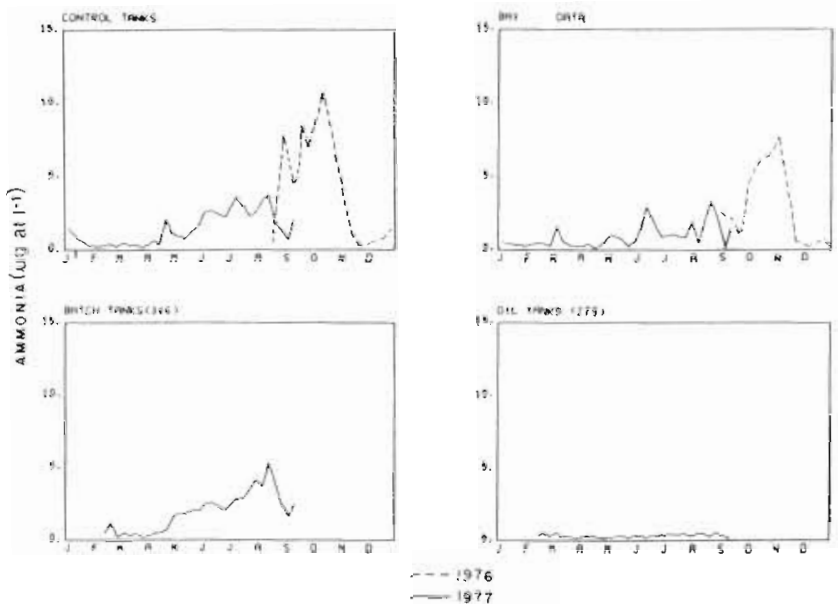

Fig. 4. Mean ammonia concentrations in microcosms and one bay station at G. S. O. dock. See Figure 2 for number of tanks and sample periods
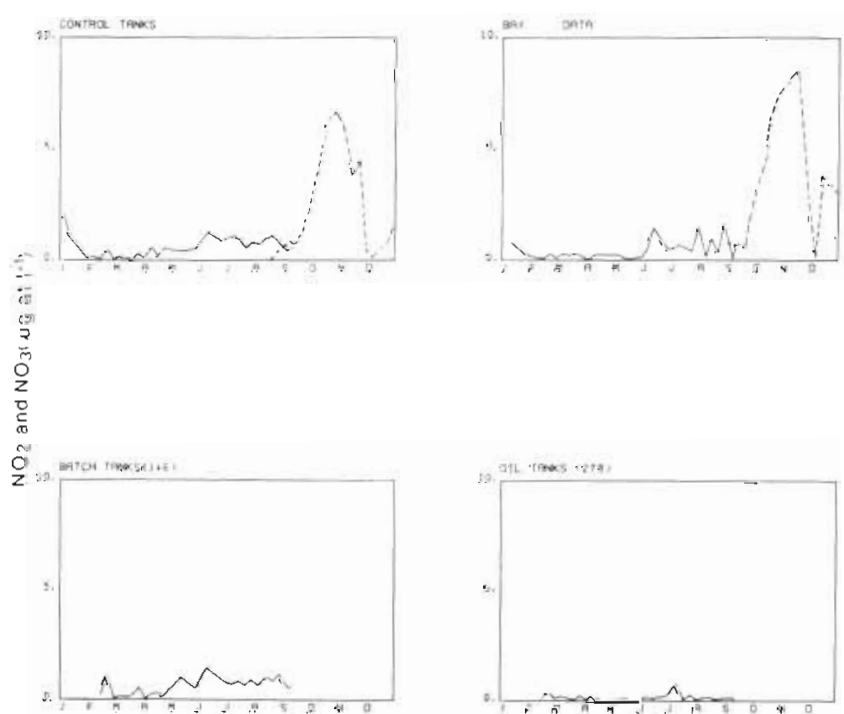

$$
\begin{array}{rr}
-.-1976 \\
-\quad 1977
\end{array}
$$

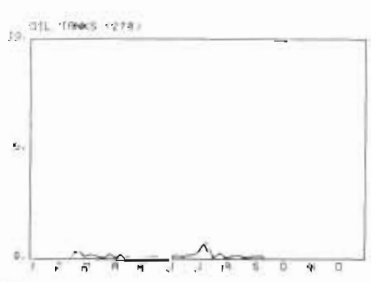

Fig. 5. Mean nitrite plus nitrate concentrations in microcosms and one bay station at G.S.O. dock. See Figure 2 for number of tanks and sample periods 


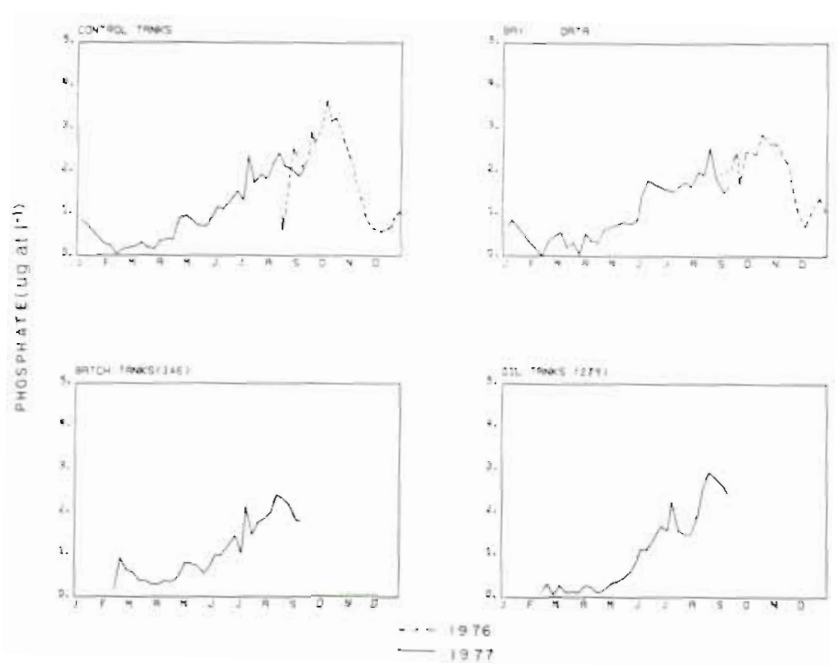

Fig. 6. Mean phosphate concentrations in microcosms and one bay station at G.S.O. dock. See Figure 2 for number of tanks and sample periods

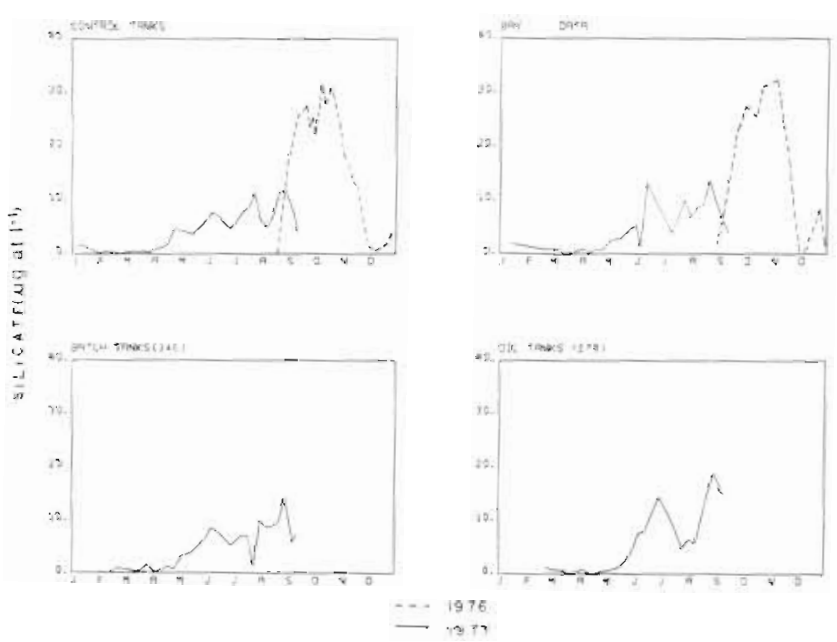

Fig. 7. Mean silicate concentrations in microcosms and one bay station at G.S.O. dock. See Figure 2 for number of tanks and sample periods

\section{Statistical Techniques}

A multivariate approach has been used in the analyses. The analyses reveal the behavior of the 9 microcosms and the 13 stations in Narragansett Bay in a 6 dimensional space defined by the variables chosen as descriptions of ecosystem behavior. The temporal behavior of each experimental unit (microcosms or bay stations) can be described by changes in the position of a vector with 6 elements corresponding to each of the dimensions in the measurement space. The advantage of a multivariate approach is that the statistical relationships among the variables defining the $p$ dimensions can be exploited and may reveal features of the data that a univariate approach would miss.

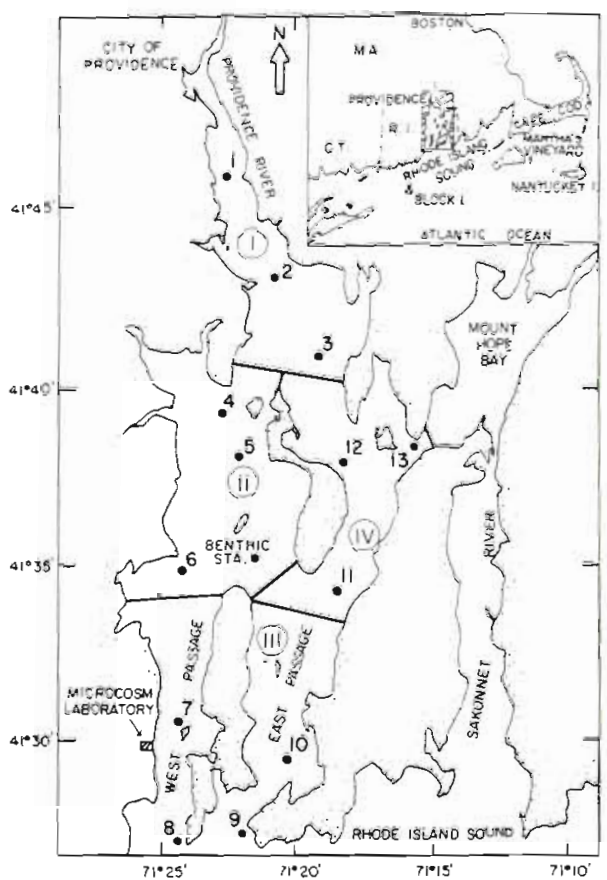

Fig. 8. Location of the 13 stations in Narragansett Bay surveyed in 1972-1973. For two of the analyses the stations (Figs 15 and 16$)$ are grouped by area: I, upper bay contains Stations $1,2,3$, II, mid-west passage, 4, 5, 6; III, lower bay, 7, 8, 9, 10; IV, mid-east passage, $11,12,13$

Formal hypothesis-testing methods based on a multivariate analysis of variance for a modified split-plot in time design allowing for both fixed and random effects, has been used to determine whether significant changes are occurring (Walker et al., in preparation) However, as Gnanadesikan (1977) indicates, the formal analyses involved in MANOVA are often not sufficiently revealing. Even though MANOVA methods are often satisfactory as a statistical test procedure since they are quite robust when underlying assumptions are not strictly satisfied, they need to be augmented by various graphical analyses. A basic difficulty in visualizing multivariate observations is that elementary plots of the raw data which take into account dependencies between the elements of the vector, cannot be made succinct enough for visual comprehension of differences. Often the dimensionality of the representation space can be reduced by transforming the original variables into a fewer number of linear components. The components then define axes of a new space which can be used to represent the data graphically. We have used this approach in the derivation of canonical variates - or discriminant axes - (Davis, 1973; Oviatt et al., 1977; Pilson et al., 1979), chosen to maximize between-group variation relative to a pooled within-groups covariance matrix. 
In this study two separate analyses involving canonical variables were performed. In the first analysis, the axes are used to maximize between treatment differences among the microcosms. The original multivariate data are then plotted in the space defined by the first two canonical axes in order to display between treatment differences as a function of time. In the second analysis, data from Narragansett Bay are also included, and the axes are used to maximize between tank and/or station differences. In both analyses the derived canonical axes are interpreted on the basis of structure coefficients (Colley and Lohnes, 1971) which are simply correlations with the original variables.

In addition to reduction in dimensionality, two measures of dissimilarity or distance were used to quantify divergences in behaviour among microcosms and stations in Narragansett Bay. The relative distances among replicate microcosms or Bay stations and between treatment groups is obviously related to the question of whether significant differences exist, and the spatial configuration of the groups provides information about the directionality of group differences (Atchley and Bryant, 1975). Gnanadesikan (1977) states: "From the point of view of data analysis, the prescription of a distance function will generally be a trial and error task in which the use of some general techniques needs to be aided by insight, intuition, and perhaps good luck!"

In this spirit, the authors have explored the data with two different statistical measures of distance, one based on the derived discriminant axes, the other on the original $p$ variable measurement space. In the distances considered, each observation $y_{t}$ (where $t$ is time and $i$ indicates tank) is considered in the context of deviations from group mean vector $\bar{y}_{i},(i=1,2 \ldots ; g$ $=$ number of groups) averaged over some time interval. As a first cut, our approach was to develop a measure of distance which was a function of the deviations from tank to tank at each time observations were made, and then to display the divergence between tanks using a plot of distance as a function of time.

Two distance metrics - (1) and (2) - are considered.

$D 1_{t i j}=\left([C] \#\left[Y_{t i}-Y_{t j}\right]^{\prime} M\left[Y_{t i}-Y_{t j}\right] \#[C]\right)^{1 / 2}$

where $Y_{t i}^{\prime}=\left(Y_{1 t}, Y_{2 t i}, \ldots Y_{p t i}\right)$ denotes a $p$ dimensional observation at a given time $t$, and the subscripts $i$ and $j$ denote different tanks (or stations); $M=A_{s} A_{s}$ is a $p x p$ matrix the rows of which contain the coefficients of the $s$ canonical variates based on the eigen analysis of $W^{-1} B$, where $W$ represents the pooled-within-groups covariance matrix, $B$ the between-groups-covariance matrix. An implicit assumption in the use of this metric is the homogeneity of the group covariance structures. $(C)^{\prime}=\left(C_{1}, C_{2}, \ldots, C_{p}\right)$ is a vector of weights the elements of which correspond to the proportion of the total variance explained by each of the canonical axes, so that $\sum_{i=1}^{p} C_{1}=1$. The operator denoted by \# is an elementwise multiplication of the two vectors, also known as the Schur or Hadamard product, and is simply used to rescale squared deviations on each of the canonical axes in proportion to the variance explained by each axis. It should not be confused with matrix multiplication.

$D 2_{t j}=\left(\left[Y_{t i}-Y_{t j}\right] M\left[Y_{t z}-Y_{t j}\right]\right]^{1 / 2}$

where $M=S_{i}^{-1}$, the inverse of the individual tank (or station) covariance matrix.

The subscripts $i$ and $j$ again denote different tanks (or stations). As Gnanadesikan (1977) indicates, when different groups are characterized by greatly different covariance structures, the metric used in (1) may not be appropriate. A measure of statistical distance to elliptical confidence regions defined by the variance covariance matrix of each group may be more revealing. Note that the distance from tank $i$ to tank $j$ (weighted by $S_{j}^{-1}$ ) is not equal to the distance of tank $j$ to tank $i$ unless $S_{i}^{-1}=S_{j}^{-1}$. With this distance matrix when the average distance from one group of $n_{1}$ tanks (or stations) to another group of $n_{2}$ tanks or stations is desired, $\left(n_{1}\right)\left(n_{2}\right)$ distances are computed and then averaged.

It should be noted that with both the derivation of the discriminant space involved in the first distance matrix, and the estimation of the individual covariance matrices used in the second matrix, variances and covariances are computed based on data accumulated over the whole time period of study. This may not be the best approach, since it fails to take into account the systematic shift in the mean values of the variables over time.

\section{RESULTS}

\section{Multiple Discriminant Analyses of Microcosm Treatment}

Multiple discriminant analyses were performed on the chosen variables from March to September 1977 and the canonical axes were interpreted using structure coefficients which show correlations between the measured variables and the canonical axes (Fig. 9, Table 2). While differences in microcosm behavior during perturbation and recovery were shown mainly by the first axis with oil tanks positioned to the left of control and batch tanks, the treatment locations along the axis were difficult to interpret. The structure coefficients indicated that different variables caused separation when the data set was partitioned by treatment (Table 2). The coefficients for the combined data set indicated that the important variables were $(+)$ zooplankton, $(-)$ chlorophyll, $(+)$ ammonia, and $(+)$ nitrite 
Table 2. Structure coefficients for microcosm oil and batch experiment February 14 to September 15, 1977

(a) First Canonical Axis, $78 \%$ of the variation explained for the combined data set

\begin{tabular}{|c|c|c|c|c|}
\hline & Combined Data & Control & Batch & Oil \\
\hline Zooplankton & $0.46^{\circ}$ & $0.52^{*}$ & $0.49^{\circ}$ & -0.07 \\
\hline Chlorophyll & $-0.56^{\circ}$ & -0.38 & $-0.47^{\circ}$ & $-0.43^{\circ}$ \\
\hline Ammonia & $0.76^{\circ}$ & $0.79^{\circ}$ & $0.83^{\circ}$ & 0.02 \\
\hline Nitrite plus nitrate & $0.76^{\circ}$ & $0.77^{\circ}$ & $0.85^{\circ}$ & $0.19^{\circ}$ \\
\hline Phosphate & 0.05 & $0.65^{\circ}$ & $0.58^{\circ}$ & $-0.83^{\circ}$ \\
\hline Silicate & -0.05 & $0.50^{\circ}$ & $0.58^{\circ}$ & $-0.91^{\circ}$ \\
\hline
\end{tabular}

(b) Second Canonical Axis, $13 \%$ of the variation explained for the combined data set

$\begin{array}{llllr}\text { Zooplankton } & -0.01 & 0.02 & 0.04 & -0.28 \\ \text { Chlorophyll } & -0.58^{\circ} & -0.28 & -0.46^{\circ} & 0.87^{\circ} \\ \text { Ammonia } & -0.25^{\circ} & -0.46^{*} & -0.38 & -0.29 \\ \text { Nitrite plus nitrate } & -0.12 & -0.27 & -0.16 & -0.17^{\circ} \\ \text { Phosphate } & -0.46^{\circ} & -0.30 & -0.49^{*} & -0.53^{\circ} \\ \text { Silicate } & -0.17^{*} & -0.02 & -0.05 & -0.34\end{array}$

- Probability $(0.0001)$ of a greater absolute correlation under the hypothesis: RHO $=0$.

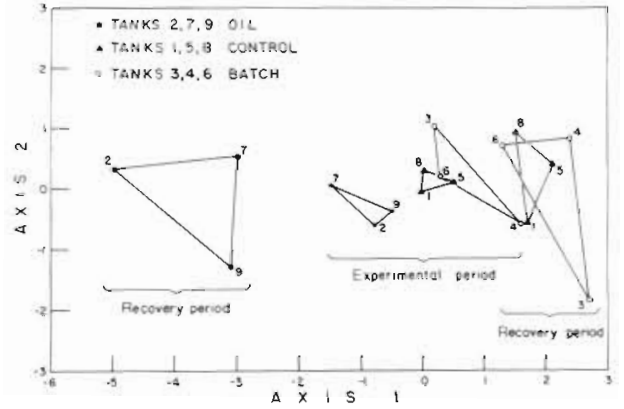

Fig. 9. Canonical axes for a data set including weekly measurements of chlorophyll, ammonia, nitrate plus nitrite, phosphate, silicate concentrations and zooplankton biomass during the chronic oil addition and no-flow (batch) experiments and during recovery period. Oil microcosms are $2,7,9$; batch microcosms, 3, 4, 6; control microcosms, 1, 5, 8. During the experimental period, the first two axes explain $78 \%$ of the variation. During the recovery period, the first two axes explain $91 \%$ of the variation

plus nitrate which might be generally interpreted as bloom versus non-bloom conditions. These correlations were not repeated in each of the partitions. For example, phosphate and silicate were not significantly correlated to the axis for the combined data set, but positively correlated in the control and batch microcosms and negatively correlated in the oil microcosms. We can, perhaps, interpret this difference in the data sets as due to different bloom species of phytoplankton using different nutrients (Vargo, personal communication),

The second axis tended to separate the batch tanks during the perturbation period (no new water flow) and both batch and oil tanks during recovery (Fig. 9). Structure coefficients indicated that the significant variables were chlorophyll, ammonia and phosphate
(Table 2). Again there were differences for the coefficients between the treatments with only ammonia significant for control tanks and only chlorophyll and phosphate significant for batch and oil tanks. In this case the significant correlations for the combined data set reflect those correlations that were significantly greater than zero when the data set is partitioned by treatment.

Another difficulty with interpreting the multiple discriminant analyses was that they do not take into account changing variability over time. The multiple discriminant space in the two analyses was based on covariance matrices using data accumulated over time. Since much of the perturbation was carried out in winter and spring when variability was low, it is possible that some portion of the greater differences in August-September reflects a greater variability in systems state (Oviatt et al., 1979).

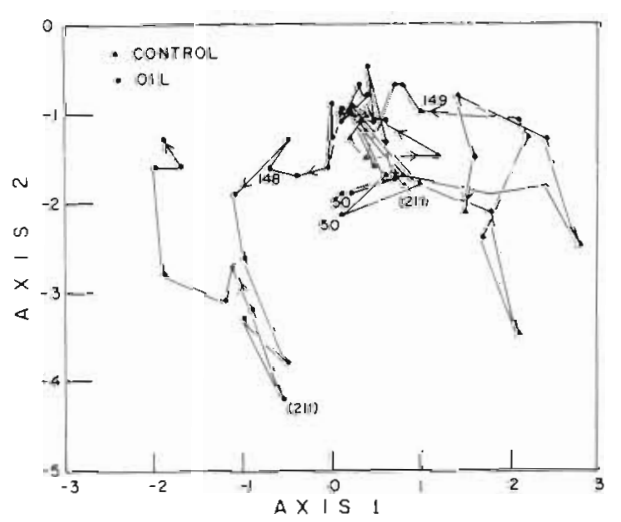

Fig. 10. Time display of mean behavior of control tanks and oil tanks. Same variables as in analysis shown in Figure 9. Numbers refer to Julian day. Oil additions ceased on Julian Day 211 
A more detailed display of the divergence of the oil and control tanks as a function of time was obtained by evaluating the first two canonical axes for the weekly treatment means. Considerable overlap occurred from February to early May (Julian 50 to 145; Fig. 10). Changes in behavior were greater during the warmer months than during the colder months for both oil and controls. Oil microcosms continued to diverge from control microcosms through the recovery period (after Julian 211). Control microcosms show a greater tendency to cycle back to earlier positions.

\section{Multiple Discriminant Analyses on Microcosms and Narragansett Bay}

Discriminant analyses were performed on a combined data set from microcosms (1977) and 13 stations in Narragansett Bay (1973) from February to September using the same variables as in the previous analyses to determine which stations in the Bay, if any, behaved similar to the microcosms. Since this combined data set included the bay stations, entirely new axes of variation could be expected. Separations between microcosm and bay stations during perturbation experiments from February 1977 to September 1977 were expressed mainly on the second canonical axis (Fig. 11). All microcosms including the oil microcosms were positioned closely adjacent with batch and controls highest on the second axis. The dock station was located between these microcosms and the oil microcosms. Next lowest on the second axis were bay stations located at the mouth of the east and west passages.
On the first axis, which we interpret as eutrophication axis because of the high correlations with all nutrients (Table 3), the Providence River was separated from bay stations and microcosms (Fig. 11). Scatter plots of the data showed a large increase in ammonia concentration in May and June for the Providence River, not present in the other partitions of the data set. Structure coefficients indicated that all variables were important for the first axis (Table 3) and that nutrients were important in the partition of the bay station and control and batch microcosms. Zooplankton and chlorophyll were important in the data partition of the oil microcosms which had low zooplankton

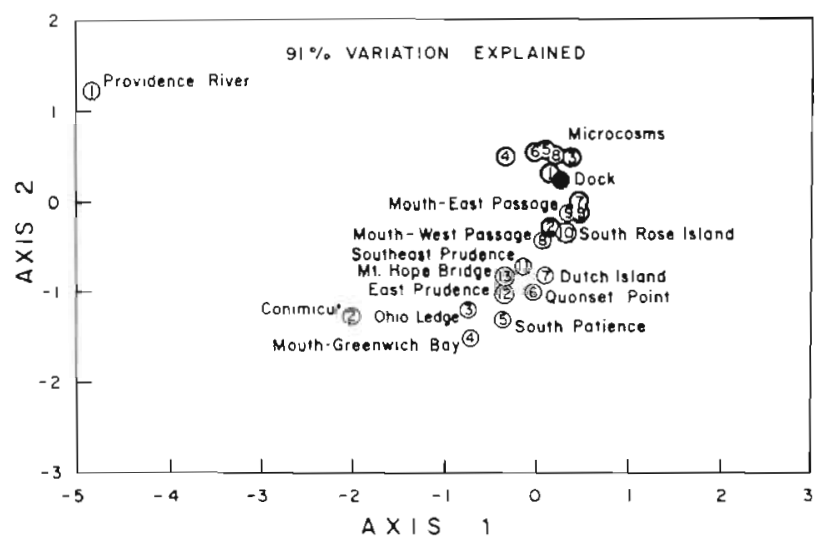

Fig. 11. Multiple discriminant analysis of temporally pooled data from 9 MERL microcosms, dock and 13 Bay stations. Variables: chlorophyll, zooplankton, ammonia, nitrate plus nitrite, phosphate and silicate. MERL (heavily circled numbers) and dock data are from February 14 to September 1977. Bay data (lightly circled numbers) are from February to September of the 1972-1973 survey

Table 3. Structure coefficients based on the combined data set displayed in Figure 11 for microcosm oil experiment February 14 to September 1977 and $1972-73$ bay survey data

(a) First Canonical Axis, 70.3\% of the variation explained for the combined data

\begin{tabular}{|c|c|c|c|c|c|c|}
\hline & Combined data & 13 Bay stations & Dock & $\begin{array}{c}\text { Control } \\
\text { microcosms }\end{array}$ & $\begin{array}{c}\text { Batch } \\
\text { microcosms }\end{array}$ & $\begin{array}{c}\text { Oil } \\
\text { microcosms }\end{array}$ \\
\hline Zooplankton & $-0.41^{\circ}$ & $-0.23^{\circ}$ & -0.41 & $-0.48^{\circ}$ & $-0.46^{\bullet}$ & $-0.52^{*}$ \\
\hline Chlorophyll & $-0.24^{\bullet}$ & -0.14 & $-0.67^{\circ}$ & -0.05 & -0.10 & $-0.61^{*}$ \\
\hline Ammonia & $-0.78^{\circ}$ & $-0.87^{\circ}$ & -0.41 & $-0.72^{\circ}$ & $-0.75^{\circ}$ & $-0.55^{\circ}$ \\
\hline Nitrite plus nitrate & $-0.77^{\circ}$ & $-0.79^{\circ}$ & -0.48 & $-0.49^{\circ}$ & $-0.49^{\circ}$ & $-0.44^{\circ}$ \\
\hline Phosphate & $-0.52^{\circ}$ & $-0.62^{\circ}$ & -0.28 & $-0.59^{\circ}$ & $-0.72^{\circ}$ & $-0.29^{\circ}$ \\
\hline Silicate & $-0.42^{\circ}$ & $-0.46^{\circ}$ & -0.24 & $-0.31^{\bullet}$ & $-0.51^{\circ}$ & -0.17 \\
\hline
\end{tabular}

(b) Second Canonical Axis, $26 \%$ of the variation explained for the combined data

$\begin{array}{lccccrr}\text { Zooplankton } & -0.51^{*} & -0.57^{*} & -0.68^{*} & -0.42^{*} & -0.24 & -0.25 \\ \text { Chlorophyll } & -0.76^{*} & -0.61^{*} & -0.84^{*} & -0.68 & -0.77^{*} & -0.88^{*} \\ \text { Ammonia } & 0.43^{*} & 0.52^{*} & 0.29 & 0.57^{*} & 0.66^{*} & 0.27 \\ \text { Nitrite plus nitrate } & 0.02 & 0.19 & 0.14 & 0.31^{*} & 0.53^{*} & 0.05 \\ \text { Phosphate } & -0.03 & 0.14 & 0.11 & 0.18 & 0.42^{*} & -0.60^{*} \\ \text { Silicate } & -0.22^{*} & -0.13 & -0.04 & 0.02 & 0.40^{*} & -0.59^{*}\end{array}$

- Probability $(0.0001)$ of a greater absolute correlation under the hypothesis: $\mathrm{RHO}=0$. 

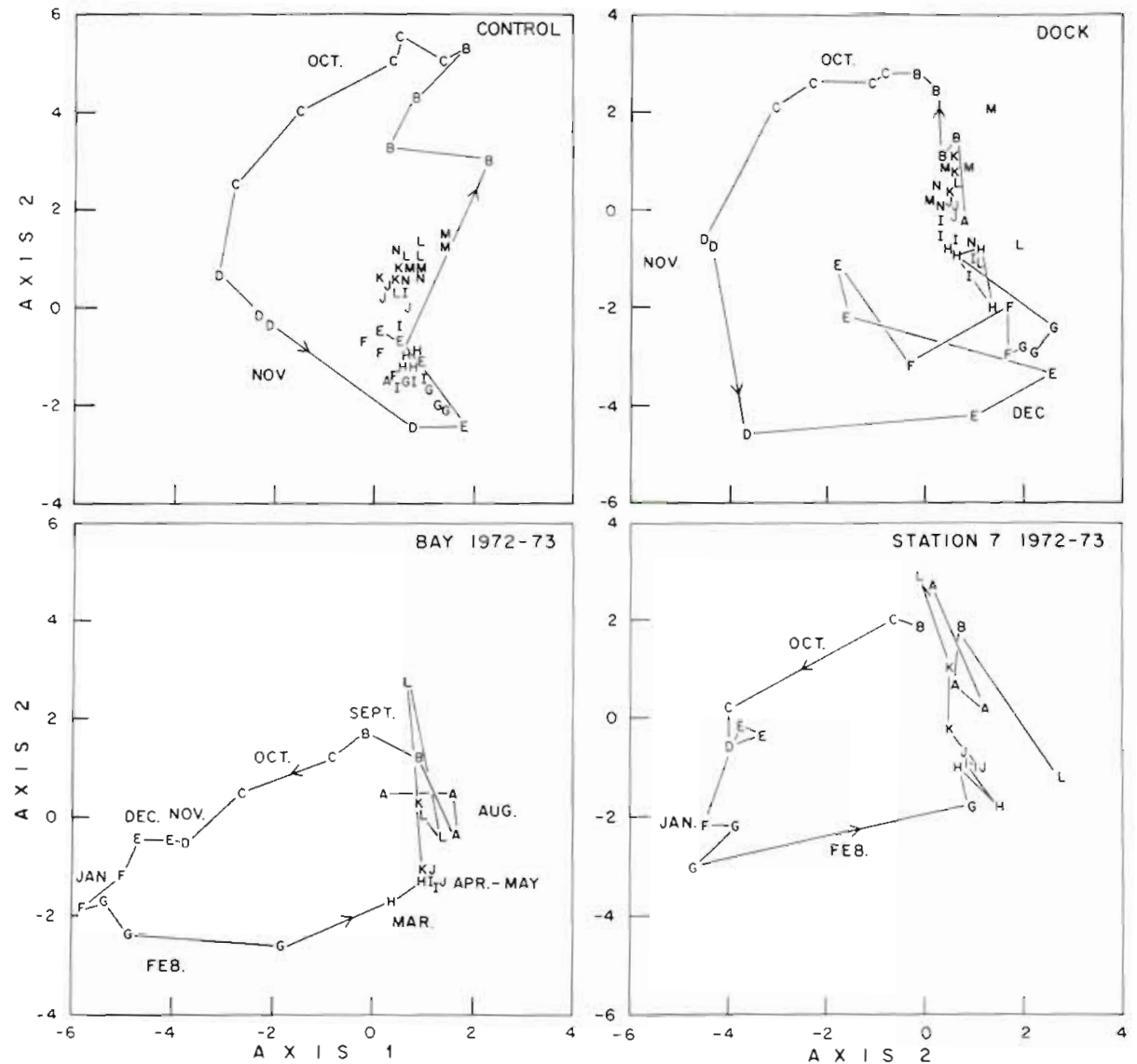

Fig. 12. Mean positions of control tanks, dock station and 13 bay stations plotted on the first two canonical axes of the discriminant analysis based on all microcosms, dock and 13 bay stations. Letters refer to month, starting with $A$ for August and ending with $\mathrm{N}$ for September

biomass and high concentrations of chlorophyll. Chlorophyll was important for the data from the dock. Structure coefficients for the second axis, which separates the microcosms from the bay stations, indicate zooplankton, chlorophyli, ammonia and silicate were important separation variables (Table 3). Structure coefficients for the various data set partitions were quite variable although chlorophyll was important in all the partitions. Data sets partitioned from the bay, dock and control microcosms had a high correlation between the second axis and zooplankton.

The first two canonical axes were evaluated weekly (bi-weekly for the 13 bay stations) and plotted serially in Figure 12 to provide additional information on the comparative behaviour of the microcosms, the dock station, Station 7, and the mean for the whole bay. All plots showed a closure of the annual cycle and were roughly similar in shape, with the mean of 13 bay stations, as expected, most different from the others. A notable difference between years was evident; this is most clearly seen in the location of data points from January (Points ' 7 ') which for both microcosms and dock station were in the lower right of the graph, while the means of the bay station were at the extreme left. The differences between microcosms and dock station appear to be less than between the dock in 1976-1977 and either Station 7 in 1972-1973, or the average of all Bay stations in 1972-1973. It, therefore, seems likely that the Bay may be more different from year to year than the microcosms were from the Bay in the one year of simultaneous measurement.

\section{Distance Analyses of Microcosm Treatment and Bay Data}

\section{Canonical Axes Weighted by Percentage Variation Explained}

The analyses indicated replicability of the microcosms within treatment groups and between control and batch treatments relative to the divergence of the oil treatment group (Fig. 13). Similarly in the bay, distances between stations within a given region were 


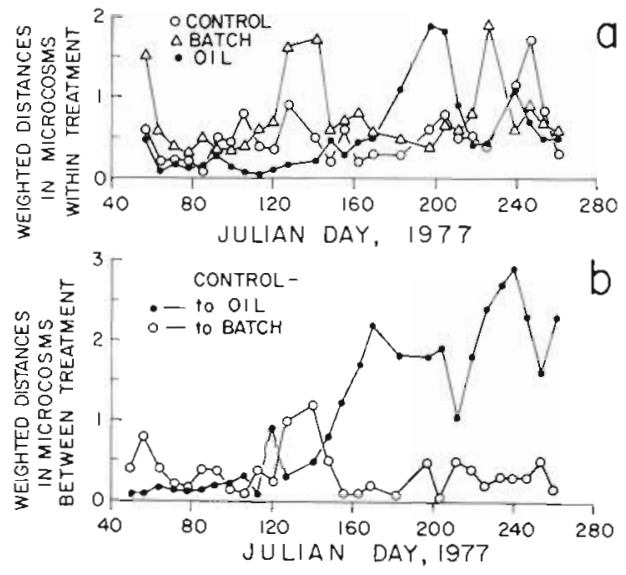

Fig. 13. Distance analysis of data from microcosms with distances weighted by percentage variation explained by the first two canonical variate axes from analysis for Figures 9 and 10. (a) Replicability within treatments; (b) distance between treatments. Oil treatment ended Day 24 (see Fig. 10)

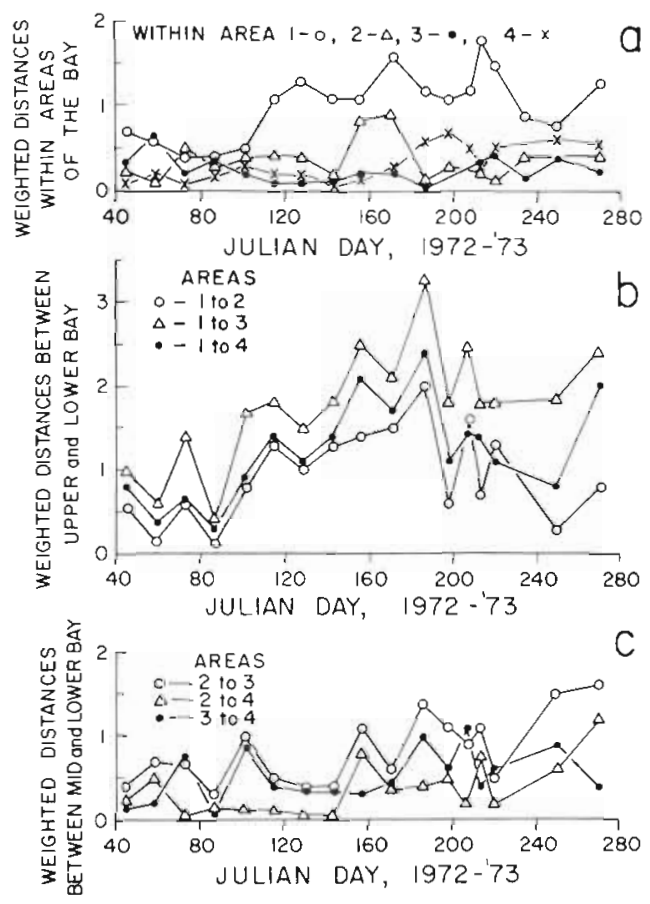

Fig. 14. Distance analyses on 1972-73 bay survey data with distances weighed by the percent variation explained by the canonical variates axes. (a) Replicability within bay areas (see Fig. 8); (b) distances between upper and lower bay; (c) distances between mid and lower bay. Since distance scales were based on their own discriminant space, they differ from Figure 13

generally smaller than distances between regions (Fig. 8, 14). However, unlike the patterns found among replicate microcosms within treatment groups, the distances among stations in the upper bay were consistently greater than for any other region (Fig. 13a, 14a). The peaks among replicate microcosms within treat- ment groups seem to indicate periods when replicate tanks were diverging. The seasonal signal appears to be stronger in the distances between areas of the bay which became greater in the summer (Fig. 14a, b) than in distances between batch and control tanks (Fig. $13 b)$.

Since the distances were weighted by the percentage variation explained by each axis, and since most of the variation was explained by the first two axes, divergences (peaks) were almost always attributable to changes along the first axis. It was, therefore, possible to observe for the individual dates which variables were responsible. Generally, divergences among replicates within treatments were due to the phasing of plankton blooms and declines. Divergences between oil and control treatments were due to a prolonged phytoplankton bloom, and a decline in nutrients and zooplankton in the oil tanks during the summer months. This interpretation was consistent with the interpretation of the structure coefficients for the combined data in Table 2. Divergences within bay areas were strongest in the upper bay, and these were due to strong gradients in nutrients. Also, divergences between bay areas were due to changes in the gradients of nutrients. Again these interpretations were consistent with the interpretation of structure coefficients for the bay data in Table 3.

Variable Space Weighted by Individual Microcosm (or Station) Covariance Matrices

As Gnanadesikan (1977) indicates, different choices of the weighting matrix can lead to quite different conclusions about the nature of a multivariate data set. In this section distance measures were calculated by weighting the squared distances by the inverse of the within-tank (or station) covariance matrices (Fig. 15, 16). The natural logarithm of the determinant of the individual covariance matrices is an indicator of the combined weighting associated with a given matrix since it is a proportional measure of the hypervolume of the scatter ellipsoid in the six dimensional measurement space (Table 4). Most bay stations were more variable than the microcosms, with the possible exception of the lower-bay stations $(8,9$ and 10). Also, the control microcosms were more variable than the oil microcosms. As a result unit changes in the original variables were given more weight in the distances weighted by the inverse of the oil tank covariance matrices. Thus distances in Figure $15 \mathrm{c}$ were generally larger than in Figure 15b. The distance metric weighed by the inverse of the oil microcosm covariances was particularly sensitive to changes in ammonia, since ammonia concentrations remained very low and had a 
Table 4. Volume comparisons (same scale) of covariance ellipsoids of data from the microcosms in 1977 and the bay in 1972-73 from February to September

\begin{tabular}{|c|c|c|}
\hline Treatment & Tank & $\begin{array}{l}\text { Natural log of the } \\
\text { determinant of the } \\
\text { covariance matrix }\end{array}$ \\
\hline Oil & $\begin{array}{c}2 \\
7 \\
9 \\
\text { Pooled }\end{array}$ & $\begin{array}{l}3.65 \\
2.78 \\
2.82 \\
5.02\end{array}$ \\
\hline Batch & $\begin{array}{c}3 \\
4 \\
6 \\
\text { Pooled }\end{array}$ & $\begin{array}{r}5.75 \\
10.92 \\
5.35 \\
8.83\end{array}$ \\
\hline Control & $\begin{array}{c}1 \\
5 \\
8 \\
\text { Pooled }\end{array}$ & $\begin{array}{l}6.32 \\
8.20 \\
5.50 \\
8.70\end{array}$ \\
\hline Bay region & Station & $\begin{array}{l}\text { Natural log of the } \\
\text { determinant of the } \\
\text { covariance matrix }\end{array}$ \\
\hline 1 & $\begin{array}{c}1 \\
2 \\
3 \\
\text { Pooled }\end{array}$ & $\begin{array}{l}20.98 \\
20.95 \\
19.06 \\
21.78\end{array}$ \\
\hline 2 & $\begin{array}{c}4 \\
5 \\
6 \\
\text { Pooled }\end{array}$ & $\begin{array}{l}20.58 \\
19.21 \\
16.73 \\
19.58\end{array}$ \\
\hline 3 & $\begin{array}{c}7 \\
8 \\
9 \\
10 \\
\text { Pooled }\end{array}$ & $\begin{array}{r}15.50 \\
9.30 \\
3.80 \\
5.55 \\
11.43\end{array}$ \\
\hline 4 & $\begin{array}{c}11 \\
12 \\
13 \\
\text { Pooled }\end{array}$ & $\begin{array}{l}11.13 \\
13.39 \\
15.24 \\
14.17\end{array}$ \\
\hline
\end{tabular}

small variance (Fig. 4). The average of the two distances may also be useful to consider (Figs 15d, 16c).

For all these distance metrics the peaks and valleys can be accounted for by directly examining the original data. For example, in Figure 15a on Julian days 183 to 204 , oil Tank 9 had very low silicate values and more diatoms compared to oil Tanks 2 and 7 . And on Julian day 239 control Tank 8 had higher zooplankton and lower silicate than control Tanks 1 and 5. Similarly, between-treatment peaks can be explained. On Julian day 120 chlorophyll was much higher and nitrogen much lower in the oil tanks than in the control tanks (Fig. 15d). On Day 253 during the recovery period oil tanks and control tanks became more similar than at any time during the surnmer. On this date zooplankton were up in control Tanks 1 and 5 and down in 8
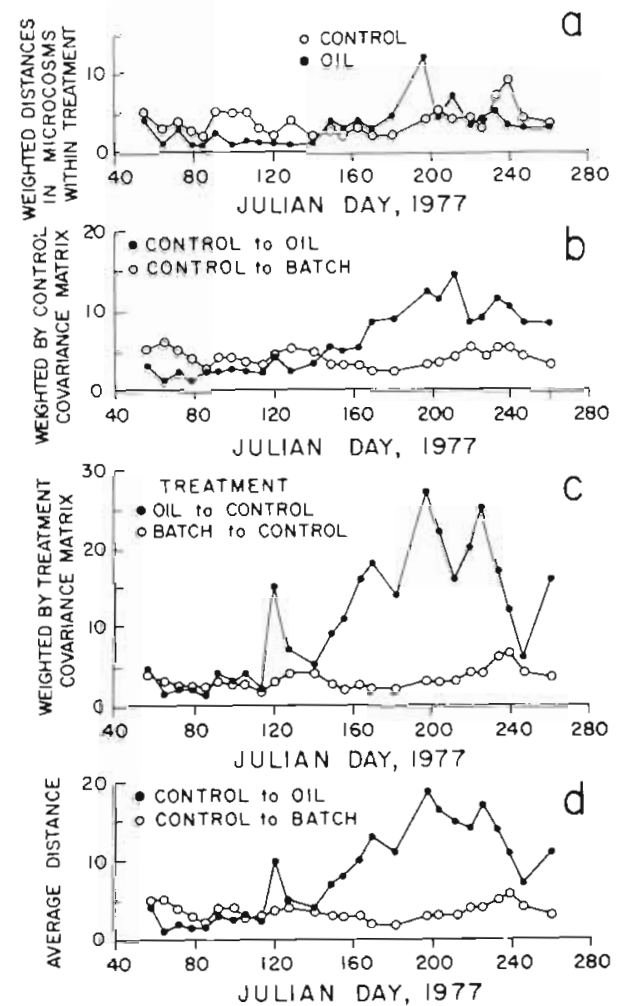

Fig. 15. Distance analysis on microcosm data with distances weighted by individual covariance matrices. (a) Replicability within treatments; (b) distance between treatments weighed by control covariance matrix; (c) distance between treatments weighed by treatment covariance matrix ${ }_{i}(d)$ average of (b) and $(c)$

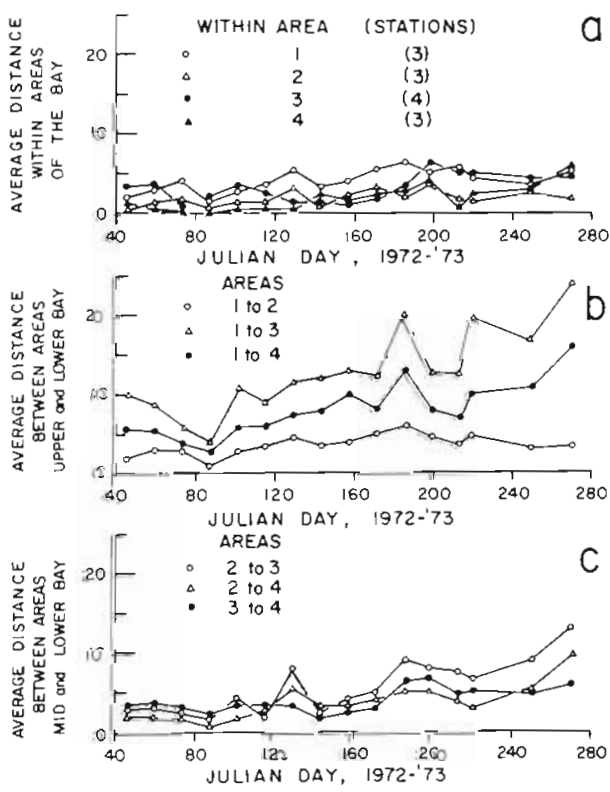

Fig. 16. Distance analyses of $1972-73$ bay survey data. (a) Replicability within bay areas; (b) and (c) area-to-area distances weighted by each, respectively, and averaged 
Zooplankton were also up in oil Tanks 2 and 7 , and became similar to oil Tank 9. Ammonia was down in control Tanks 5 and 8 , and up in Tank 1 . Control Tanks 5 and 8 were similar to oil Tanks 2,7 and 9 . Chlorophyll was lower in the oil tanks and higher in the control tanks than previously. Generally, during the summer, chlorophyll was higher, and nutrients and zooplankton were lower in the oil tanks than in the control tanks. Day 253 was a reversal of this trend.

\section{DISCUSSION}

\section{Statistical Techniques}

The objective of this paper was to attempt a synthesis of several kinds of data from measurements in ecosystems so that perturbed and natural systems may be compared and rates of perturbation and recovery be evaluated. Since statistical models involving univariate responses are not sufficiently sensitive indicators of total system behavior, multivariate response models were used. However, we found that MANOVA models need to be augmented by other analyses since we believe that there is not necessarily a close correspondence between the statistical significance of a difference and its substantive importance in understanding ecosystem behavior Thus we explored the correlations of original variables with linear components designed to display variation in fewer dimensions, along with the use of distance statistics to describe the process of divergence in behavior.

The results from the MANOVA (Walker et al., in preparation) illustrate the problem of interpreting results using statistical significance tests alone. Since plankton blooms may start at slightly different times among replicates within a given treatment, it would be possible to detect significant differences in temporal profiles for replicate tanks within treatment groups if data were available. Despite such differences in the phasing of these cycles, which it may not be possible or even desirable to control, the overall functional behavior of replicates within a treatment may be quite similar. With ordinary statistical test procedures it seems possible that larger patterns of behavior may be missed so we have tried some other approaches.

Multiple discriminant analyses (canonical variates) were used to explore the major axes of variations between treatments and the natural system. While this appears to be a common practice in the literature, we found that this type of analysis is difficult to interpret without structure coefficients (Tables 2-3). Even then, usually only the first axis can be interpreted even though the second axis was sometimes important in displaying differences. The individual partitions of the data sets do not have the same patterns of correlations as the combined data sets. Nevertheless, the correlations in the combined data sets often have a pattern which can be interpreted. In the microcosm perturbation experiment the opposite correlations between chlorophyll, nutrients, and zooplankton with the first axis were indicative of bloom dynamics of plankton (Table 2). When the microcosms and the bay were analyzed together, the high correlations for nutrients on the first axis was indicative of a nutrient or eutrophication gradient (Table 3). Multiple discriminant analyses do not take into account changing variation with time (seasonal effects). Consequently, we have made time varying plots (Fig. 10,12) which somewhat successfully indicate differences due to treatment and season.

Two distance metrics have been explored to search for criteria for natural and perturbed states. Even though the statistical distributions of these distances are unknown, bath distance statistics were useful for indicating obvious features in the divergences among replicate tanks and within bay areas and between treatment groups and bay areas. The relative patterns of within and between distances for both microcosms and bay stations were interpretable. With both distance statistics the divergence among replicate tanks within a treatment could be related to lag effects in the dynamics of plankton blooms. Divergence among treatment groups could be related to substantial changes in the functional behavior of the microcosms.

\section{Holistic Behavior}

These analyses have provided an overview of events in the microcosms with regard to the variables used. Differences and similarities between treatments were graphically indicated along with the important variables for the experiments as a whole over time. Oil, batch and control microcosms had overlaps in their behavior during the spring months of the experiment. Divergence in behavior between oil and control microcosms occurred during summer and continued in the early fall. Batch and control tanks did not diverge.

The analyses have also indicated how the microcosms behaved compared to Narragansett Bay in 1972-1973. On the basis of mean vectors which ignore systematic changes over time, the location of the control microcosms in multiple discriminant space was close to but did not overlap the mid-bay stations (Fig. 11). The dock station in 1976-1977 also was separated from the 1972-1973 bay stations, indicating that the major difference between the microcosms and the bay stations may be due to year to year differences in the bay (Fig. 12). An interpretation based on the grand 
means would be that the microcosms were lower in phytoplankton in batch and control microcosms and lower in zooplankton and nutrients in oil microcosms than the bay was in earlier years.

Despite some dire predictions by critics of microcosm methodology, examination of the data indicates that the behavior of the microcosms was in many ways similar to that of the bay input water which (unlike the 1972-1973 data) was measured concurrently. We can also observe some of the effects of the oil treatments (also see Elmgren et al, in press). Chlorophyll concentrations were generally lower in the control and batch tanks than in the bay input water, although the spring diatom bloom occurred on time (Fig. 2). Chlorophyll concentrations in the oil tanks were elevated over the bay, but the seasonal patterns were very similar. Zooplankton biomass in the control and batch tanks were generally lower than the bay but reached similar peak concentrations in the summer (Fig. 3). Oil tanks had very reduced populations of zooplankton. Nutrient concentrations tended to be similar to the bay in control and batch microcosms (Fig. 4-7). Ammonia, nitrite plus nitrate were much lower in the oil microcosms, and phosphate and silicate were similar to bay concentrations.

A question remains as to whether the multivariate techniques we have used are more useful than visually interpreting plots of the response of individual variables over time. Given the knowledge of the structural and functional relationships among the variables, it is not clear that anything new was learned using these techniques. Significance tests would indicate that the differences were real, but for many of the variables these differences were dramatic enough that they were obvious when the data were plotted. Attempts to reduce the dimensionality of the representation space did provide a summarization of the data and resulted in interpretations in agreement with raw data time series analyses. The distance metrics have roughly quantified the magnitude of divergence in microcosm behavior and compared this behavior with the natural system. In addition, the distance metrics can be related to the functional and structural responses of the microcosms. At present these distances appear to be useful for comparing microcosms and natural systems in a holistic manner.

Acknowledgements. We thank the individuals at MERL who were responsible for data collection including Gabriel Vargo and his associate Melissa Hutchins, and Sandra Vargo and her associate Rose Lambert. We are also indebted to Jerilyn Mearns for computer processing of the data and Enesto Lorda for help with data analysis. Björn Malmgren and two unknown reviewers helpfully critized the manuscript. This work was supported by EPA grant R8039020.

\section{LITERATURE CITED}

Atchley, W. R., Bryant, E. H. (eds.) (1975). Multivariate statistical methods, Among Groups Covariation. Dowden, Hutchinson \& Ross, Inc. Stroudsburg, Pennsylvania

Bodungen, G., Gocke, K., Smetacek, V., Zeitzschel, B, (1976). The plankton tower. III. The effect of sediment flushing by density displacement of interstitial water on pelagic primary production and microbial activity. Kieler Meeres. forsch. 3: 87-95

Cooley, W. W. Lohnes, P. R. (1971). Multivariate data analy sis, Wiley \& Sons, Inc., New York

Davies, J. M., Gamble, J. C., Steele, J. H. (1975). Preliminary studies with a large plastic enclosure. In: Cronin, L. E (ed.) Estuarine research, Vol. 1. Academic Press, New York, pp. 251-264

Davis, J. C. (1973). Statistics and data analysis in geology Wiley \& Sons, Inc., New York

Degobbis, D. (1973). On the storage of seawater samples for ammonia determination. Limnol. Oceanogr. 18: 146-150

Elmgren, R., Grassle, J. F., Grassle, J. P., Heinle, D. R., Langlois, G., Vargo, S. L., Vargo, G. A. (in press). Trophic interactions in experimental marine ecosystems perturbed by oil. Symposium on microcosms in ecological research. Savannah River Ecology Laboratory, Nov. 8-11, 1978, August, Georgia

Frederick, G. O., Whitledge, T. (1972). Autoanalyzer procedures for nutrients. In: Parlou, S. D. (ed.) Chemostate methodology and chemical analyses. Dept. Oceanography University of Washington, Seattle. Spec. Rep. 52: 38-60

Gearing, J. N., Gearing, P. J., Wade, T., Quinn, J., McCarty, H., Farrington, J., Lee, R. (1979). The rates of transport and fates of petroleum hydrocarbons in a controlled ecosystem (MERL), and a note on analytical variability. 1979 Oil Spill Conference (Prevention, Behavior, Control, Cleanup), Los Angeles, California, March 19-22, 1979

Gnanadesikan, R. (1977). Methods for statistical analysis of multivariate observations, Wiley, New York

Holm-Hansen, O., Lorenzen, C. T., Holmes, R. W., Strickland J. D. H. (1965). Fluorometric determination of chlorophyll. J. Cons. perm. int. Explor Mer 30: 3-15

Hood, D. (1977). Editorial: Controlled ecosystem pollution experiment with emphasis on mercury. Mar. Sci. Comm. 3: 289

Lorenzen, C. J. (1965). A note on the chlorophyll and phaeophytin content of the chlorophyll maximum. Limnol. Oceanogr. 10: 482-483

Menzel, D. W. (1977). Summary of experimental results: controlled ecosystem pollution experiment. Bull. mar. Sci. 27: 142-145

Oviatt, C. A., Nixon, S. W., Perez, K. T., Buckley, B. (1979). On the season and nature of perturbations in microcosm experiments. In: Dame, R. (ed.) Marsh-estuarine systems simulations. Eighth Belle W. Baruch Inst. Mar. Biol. and Coastal Research Symposium, Georgetown, South Carolina. January 1977, pp. 143-164

Oviatt, C. A., Perez, K. T., Nixon, S. W (1977). Multivariate analysis of experimental marine ecosystems: results for Narragansett Bay. Helgoländer wiss. Meeresunters. 30: $30-46$

Perez, K. T., Morrison, G. M., Lackie, N. F., Oviatt, C. A., Nixon, S. W., Buckley, B. A., Heltshe, J. F. (1977). The importance of physical and biotic scaling to the experimental simulation of a coastal marine ecosystem. Helgoländer wiss. Meeresunters. 30: 144-162

Pilson, M. E. Q., Vargo, G. A., Gearing, P., Gearing, J. N. (1977). The Marine Ecosystems Research Laboratory: A 
facility for the investigation of effects and fates of pollutants. In: Proceedings, 2nd National Conference Interagency Energy/Environment R \& D Program, Washington, DC. June 1977, pp. 513-516 in EPA-600/9-77-102

Pilson, M. E. Q., Oviatt, C. A., Vargo, G. A., Vargo, S. L. (1979). Replicability of MERL microcosms: Initial observations. pp. 359-381. In: Jacoff, F. S. (ed.) Advances in marine environmental research. Proceedings of a symposium, June 1977, U.S. EPA, Narrangansett, Rhode Island

Smetacek, V., von Budungen, B., von Brockel, K., Zeitzschel, B. (1976). The plankton tower. II. Release of nutrients from sediments due to changes in the density of bottom water. Mar. Biol. 34: 373-378
Solórzano, L. (1969). Determination of ammonia in natural waters by the phenolhypochlorite method. Limnol. Oceanogr. 14: 799-801

Steedman, H. F. (1976). Zooplankton fixation and preservation, Monographs on oceanographic methodology 4, The UNESCO Press, Paris

Steele, R. G. D., Torrie, J. H. (1960). Principles and procedures of statistics, McGraw-Hill Book Co., New York

Tranter, D. J. (ed.) (1968). Zooplankton sampling, Monographs on oceanographic methodology 2, The UNESCO Press, Paris

Walker, H. A., Lorda, E., Oviatt, C. A. (in prep.). A statistical microcosm model with fixed and random effects for multivariate time series data

This paper was presented by Dr. M. Levandowsky; it was accepted for printing on February 7, 1980. 